\title{
Using Virtual Reality Technology to Develop Performance on the Treadmill
}

\section{Dr/ Ahmed Abd Elmonim Alsuofy ${ }^{*}$}

\section{Introduction:}

Virtual reality is important novel software, It's refers to the development of an artificial 3-dimensional setting that draws on one or more of the user's senses, and the interaction of these senses depends on the active engagement of the user.(2) "Hsiu\&Sheng"(2010)

note that virual reality technology has become popular in the last few years, and has been successfully used in educational applications, as it resemble the real world. Through virualreality a different setting that simulates a reality where the individual can reach or live can be established. It makes the user engaged and involved in the setting it self and engage one's senses so that one experiences something that resembles reality to great extent, but not true.(14)

"Wai, Che,et al" (2010), "Elirda,et al" (2009), "Joan Mccomas et al" (2006), and "Mhryar" (2005) emphasize that virtual reality is an excellent educational tool in the physical (skills) and the cognitive domains, Using it as a tool becomes more substantial when presenting various experiences.

Studying sports kinetic behavior is a branch of Kinesiology, The outcome of kinetics in the field of sports is not random, but has a clear objective the person aims to achieve.

Evaluating the level of kinetic performance objectively depends mostly on the evaluation means used. The more accurate and reliable this means is, the more objective the evaluation becomes and the more valuable are the data that result from such evaluation. (12) (22)

Modern life, accompanied by lack of motor and physical activities as a result of the technological and technical advancements, Aerobic activities where performance of the basic human movements

*Assistant Professor, Department of Sport Movement Science, Faculty of Physical Education for Boys, Helwan University, Egypt 
continues for a long time such as walking and running, plays a fundamental role in any motor program that can be followed. Such activities have positive effects in maintaining good health and fitness, maintaining ideal weight, as well as reducing the like lihood of diabetes and cardiovascular diseases. However, the element of interest should be added to walking and running activities in order to increase motivation of participation (1). (20).

Additionally, the World Health Organization (WHO) reports point out that lack of exercising results in the lack of fitness and balance makes the individual more prone to falling, whichis considered the second reason of mortality resulting from accidental and unintentional injuries in the world.

It's estimated that (424000) persons die annually around the world due to lack of physical fitness and falling, as well as (37.3) million persons require medical care due to falling (24).

It's established that walking and running can take place in different environmental and climate conditions. These conditions may have an effect on the individual's health and integrity. God has provided humans with high capacity to tolerate different temperatures and respond to these changes. Human vital organs perform their functions irrespective of the outside temperature. Nevertheless, high or low temperature, dust, and air pollution`s considered hazardous to human health. Walking and running are important for athletes, nonathletes and all ages, as well as the lack in fields or parks that provides individuals with a suitable space for running/walking on a suitable ground, using the treadmill has become a good choice. The researcher has observed a state of boredom that the individual may experience during running/walking on the treadmill.

Therefore, sought with the virtual reality laboratory team at the Faculty of Engineering, Ain Shams Univ, to find a mechanism that creates a competitive atmosphere, a virtual involvement of the user, interaction in terms of vision and hearing, and control of all the variables of running 
including distance, speed, competition, and place of performance, during one's performance on the treadmill. This aims at increasing individual's interests, motivation, positive attitudes, positive participation opportunities, which makes them enjoy the performance at low cost.

"Gama MC,et al"(2016), "Hanley\& Mohan" (2014),"Brien" (2011)"Clark, RA,et al" (2010), agree on applying virtual reality technology to the treadmill and the benefits of using the treadmill such as maintaining good health, increasing fitness, and keeping balance for elderly people. "Iruthayarajahet al" (2016),"Lee IW, Kim" (2015),"Cho, Sohng" (2014) and "Cho GH, Shin HS" (2014), found an association between applying virtual reality to the treadmill and improving stepping problems in youth and elderly persons as well as brain stroke patients. "Mulroy et al" (2010), "Jeong HW" (2008) and "Barak Y et al" (2006) point out the importance of laboratory tests to study walking and running. Research Terms:
Virtual reality, Video tracking, Treadmill

\section{Research Objectives:}

Using virtual reality technology in designing and developing a treadmill that can interact with the virtual performance environment.

\section{Research hypotheses:}

1. Improvementrate of speed to the study sample (youth elderly) on the proposed Treadmill.

2. Increase the distance covered to the study sample (youth - elderly) when they make Cooper test.

\section{Research Methods:}

The researcher uses the descriptive and experimental methods to link the used tools and devices with the virtual reality technology.

\section{Research Population and Sample:}

The research population consists of (6) students at the Faculty of Engineering, and (6) employees at the Faculty of Engineering, Ain Shams Univ, over (55) years old and who suffer from osteoarthritis and inability to move effectively.

\section{Used tools:}

- $\quad$ A treadmill (Oma 600)

- Kinect with a video tracking analysis program 


\section{- A laptop - 2 LED} screens

- $\quad$ Other electronic parts to connect the treadmill to the Kinect to display on the screen.

\section{The proposed device:}

The main idea of the device is spontaneous interaction between user and treadmill without using a control pad, and transform the performance on a treadmill to an engagement with display screen with possibility of

\section{A. How the device works:}

The technical aspects: a junction inside the treadmill's control pad has been done that transform the alternating current (AC) to direct current (DC) multi-level according to the required speed (figure2-A).

Altering speed has been controlled by pulse width modulation, which is a percentage that can be used to link currents (v_out $=d \times v \_$in) Thus, the DC value, using this simple idea, dcmotors, can be controlled.(25)

Motion analysis:

Kinect monitor and track the human joints and transmit directly to the control unit (figure 3), has been used, The Kinect has been set on a tripod Assiut Journal For Sport Science Art selecting from many conditions for performance, in order to stimulate the individuals who walk/run on the treadmill by creating a virtual audio-visual competitive environment, This`s similar to the interactive racing computer games (Subway Surfers) where the player can sue the level of competition, distance, running place, and listen to motivating guidance.

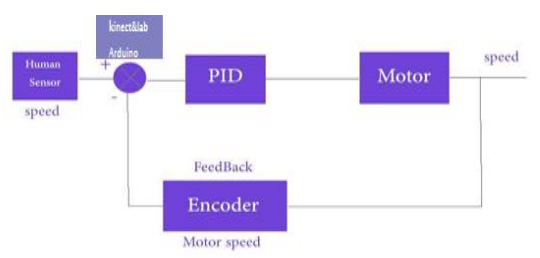

System Block Digram

Figure 1: how the system works
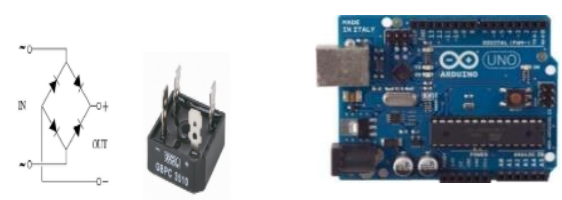

A

B

Figure 2: The circuit used to transfer the electric current

over the treadmill, $150 \mathrm{~cm}$ high and $2 \mathrm{~m}$ away from treadmill, Kinect analyses and tracks the body joints at 30

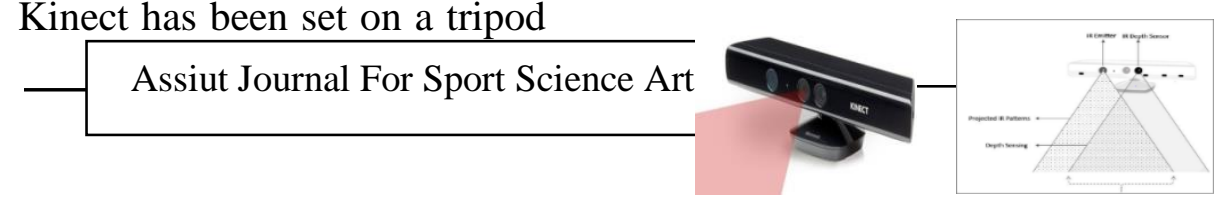

Figure 3: description of the Kinect's role 
frames/second.

Speed controlled by an equation of distance by subtracting the virtual and horizontal dimensions of the head in each frame. Result transformed into analog signal that transmitted to control unit. Therefore, when the head speed in a frame Result of the speed equation transmitted to control unit's Arduino (figure 2-B)(25) then it transmitted to the pulsewidth modulation (PWM) which transmits it in voltage to the motor in order to increase or decrease the treadmill's speed. Arduino is the part that receives orders from the control unit. Its function is to make the computer feel and control the surrounding environment by a simple control platform. It sends orders that transmit what happens to the computer screen.(26)

Control unit's PID adjusts and complements previous and current motor speeds, and anticipates the next is greater than the previous frame, Speed increases and vice versa $(v=d 1-d 2)$ Once Kinect monitors the head moving forward, it calculates the difference in distance between two positions and time, then concludes speed.(10)

speed through analyzing the results of the Kinect's equation, in order to analyze the user's movement through several previous and current frames, send orders with the anticipated speed so that no sudden changes occur due to the random body movements (wiping sweat, drinking water, adjusting clothes, etc.) which may change the body center of gravity (figure 4).(27)

PID = Proportional + Integral + Derivative Proportional mode: reacts to the present error

Integral mode: reacts to the past history of the error signal Derivative mode: reacts to the expected future of the error signal (rate)

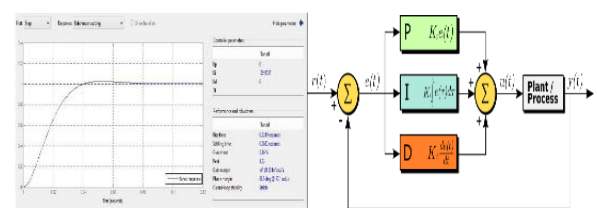

Figure 4: Equation of sending orders

from the PID to the treadmill's motor

$\mathrm{TF}=\mathrm{Kp}+\mathrm{Kis}+\mathrm{Kds}$

This is the idea devices. In the presence of beyond artificial intelligence previous information, the Assiut Journal For Sport Science Arts 
current situation interpreted, and the future anticipated.

Displaying the event on the graphical or virtual reality display screen occurs using Unity 3D, which is used in the tracks of racing games (Subway surfers), Arduino unit linked to the track that the user wants to run/walk in. It provides both the track and the treadmill with the real speed the of the user's movement.

Difficulty can increase by using the treadmill's incline unitThis displayed on the screen in the form of bridges or graphical incline.

To end the running session, the user moves his/her head backward and slows down.

For the user's safety and security, in the case of falling, a safety tape activated for stopping immediately.
Additionally, in case the Kinect tracks a quick unexpected movement of the head on the axes xyz, the program immediately stopped.

Main application of the Research:

The implementation of the idea of the device started in April 2013, and it reached the final version in January 2014.

The device's validity coefficient:

The researcher used concurrent validity, as he conducted Cooper Test of walking/running for minutes on the treadmill without switching on the Kinect or the screen, then the test has conducted after two days to ensure recovery with the whole system on. Correlation Piarson coefficient has calculated through the results of the two measurements.

\section{Table (1)}

Correlation between results Cooper test on the proposed device and Normal traidmill for the research sample $(n=12)$

\begin{tabular}{|c|c|c|c|c|c|c|}
\hline \multirow[t]{2}{*}{ Sample } & \multirow[t]{2}{*}{$\overline{\text { Test }}$} & \multicolumn{2}{|c|}{$\begin{array}{c}\text { Normal } \\
\text { traidmill }\end{array}$} & \multicolumn{2}{|c|}{$\begin{array}{c}\text { proposed } \\
\text { device }\end{array}$} & \multirow[t]{2}{*}{$\begin{array}{c}\text { (r) } \\
\text { Value }\end{array}$} \\
\hline & & Mean & SD & Mean & SD & \\
\hline students & $\begin{array}{l}\text { Cooper test } \\
\text { (m) }\end{array}$ & 1541.66 & 37.237 & 1591.6 & 30.6 & $* 0.918$ \\
\hline
\end{tabular}




\begin{tabular}{c|l|c|c|c|c|c}
\hline \hline & Calories & 104.833 & 9.02 & 116.16 & 4.35 & $* 0.887$ \\
\hline elderly & $\begin{array}{l}\text { Cooper test } \\
(\mathrm{m})\end{array}$ & 1541.66 & 37.237 & 1591.6 & 30.6 & $* 0.913$ \\
\cline { 2 - 7 } & Calories & 104.833 & 9.02 & 116.16 & 4.35 & $* 0.866$ \\
\hline \hline
\end{tabular}

Tabular value of $r=0.829$ 
Table (1) that outlines the results of the Cooper test, demonstrates that the average distance walked/ran in (12) minutes on the treadmill for the students in the research sample was (1541) meters, while it was (1591) meters on the proposed device. This indicates an increase by (50) meters. With respect to elderly participants, the average distance walked/ran on the treadmill during the Cooper test was (1041) meters, while it was (1096) meters on the proposed treadmill. This indicates an increase by (55) meters.

This shows that the average speed of students on the treadmill during the Cooper (12-minute) test was (7.7) $\mathrm{km} / \mathrm{h}$, but increased to (7.96) $\mathrm{km} / \mathrm{h}$ with the virtual reality

\section{Table (2)}

The correlation coefficient between the test and re-test the results of the proposed device in a sample search $(n=12)$

\begin{tabular}{c|c|c|c|c|c|c}
\hline \hline \multirow{2}{*}{ Samble } & \multirow{2}{*}{ Test } & \multicolumn{2}{|c|}{ Test } & \multicolumn{2}{c|}{ ReTest } & \multirow{2}{*}{ (r) } \\
\cline { 3 - 7 } & & Mean & SD & Mean & SD & Value \\
\hline \hline \multirow{2}{*}{ students } & time & 22.5 & 1.048 & 22.33 & 1.032 & $* 0.911$ \\
\cline { 2 - 7 } & step & 8.04 & 0.371 & 8.03 & 0.456 & $* 0.875$ \\
\hline \multirow{2}{*}{ elderly } & time & 32.0 & 1.78 & 31 & 1.264 & $* 0.983$ \\
\cline { 2 - 7 } & step & 11.1 & 0.576 & 11.28 & 0.81 & $* 0.865$ \\
\hline \hline
\end{tabular}

Shown in Table (2) of the study sample of students and the elderly and that there is a high correlation between the technology. Moreover, the average speed for elderly participants was (5.2) $\mathrm{km} / \mathrm{h}$ during the Cooper (12-minute) test, but the average speed increased with virtual reality technology to $(5.48) \mathrm{km} / \mathrm{h}$.

Reliability coefficient of the test:

The researcher used the way the test and re-test to measure through the video recording video recorded the sample using a digital camera during performing on the treadmill at the speed of (4.5) $\mathrm{km} / \mathrm{h}$ for (20) meters in order to qualitatively analyze the number of steps, their duration, and compare them to what is displayed by the Kinect to the screen, then calculate the standard deviation of each player's results (Table 2). 
meters. The total number of steps for the students of the correlation coefficient (0.875) and elderly (0.865), which shows the sincerity of the device to measure the position of the measure.

Note: (time) refers to the time registered on the machine again Step; refers to the number of steps.

\section{Results:}

The researcher reached the following results through the practical application of the proposed device:

Table (1) Showed the Cooper test results indicated that the average distance in (12 min) of the sample of students on normal Treadmill record (1541), and the proposed Treadmill were $(1591 \mathrm{~m})$, which indicates a rise in distance by $(50 \mathrm{~m})$, but for the elderly was the average distance during the walk onnormal Treadmill performance is Cooper test $(1041 \mathrm{~m})$, while with the use of the proposed electric walking distance of cut (1096), an increase of $(55 \mathrm{~m})$.

Which shows that the average speed of the students on the normal Treadmill during the performance of the Cooper test for (12) minutes $(7.7 \mathrm{~km} /$ h), while the improved with virtual reality technology to (7.96 km / h),

As for the elderly was the average speed on the normal Treadmill during performance the Cooper test (12) minutes $(5.2 \mathrm{~km} / \mathrm{h})$, and improve the average speed with VR technology by $(5.48$ $\mathrm{km} / \mathrm{h}) .(23)$

\section{Conclusions:}

1. Cooper test results for both the treadmill and the proposed treadmill indicate an increase of the average distance walked/ran by young participants by 50 meters $(3.25 \%)$, and an increase in the average distance walked/ran by elderly participants by 55 meters $(5.28 \%)$ in favor of the proposed treadmill. Thus, the first hypothesis is supported.

2. The average speed for young participants improved by $0.26 \mathrm{~km} / \mathrm{h}(3.37 \%)$ in favor of performance on the proposed virtual reality treadmill. Additionally, the average speed of elderly participants improved by 0.28 $\mathrm{km} / \mathrm{h}$ (5.38\%). Thus, the second hypothesis is supported. 3. All options work and can be used and watched on the two screens while running, even though they were 
somehow slow. The work team has replaced the display card with a more advanced one to ensure the quick loading of the video on the screen.

4. The control unit's temperature increased with the increase of speed or duration. Therefore, the work team added a fan to the control unit.

5. Performing on the treadmill for more than 15 minutes results in the burnout of an important IC. To resolve this issue, the work team searched for a dual valve called transient-voltage-suppression (TVS) diode. However, it is not available in Egypt and other TV valves have been used to solve part of the problem.

\section{Recommendations:}

6. The researcher recommends using the proposed device in clubs and gyms.

7. Using virtual reality technology in sports that require attention and perception such as gymnastics, diving, and ballet.

8. The researcher recommends using the proposed device to improve stepping movement in brain stroke patients.
9. The researcher recommends using these scientific technologies in other applied aspects in the fields of sports.

10. Using the device in experimental research to measure speed and cardiorespiratory endurance.

\section{References:}

1. Abdul Aziz Karim, Kazem Mohammed (2009); contemporary topics in physical education Translation Center and copyright - King Faisal UnivRiyadh (88)

2. Ahmed Abd Elmonim Elsoufy (2012): Movement Science Traditional and Contemporary, DarrFekrah, Cairo.pp 187

3. Barak Y., Wagenaar R., and Holt K. 2006: Gait Characteristics of Elderly People with a History of Falls: A Dynamic Approach Phys Ther 86(11): 1501-1510,.

4. Brien M, Sveistrup H: 2011: An intensive virtual reality program improves functional balance and mobility of adolescents with cerebral palsy. Pediatr Phys Ther, 23:258-266.

5. Cho

GH, Hwangbo

G, Shin HS (2014): The Effects of Virtual Realitybased Balance Training on Balance of the Elderly. 
6. Cho H, Sohng KY 2014: The effect of a virtual reality exercise program on physical fitness, body composition, and fatigue in hemodialysis patients

7. Clark R, Bryant A, et al.(2010),: Validity and reliability of the Nintendo Wii Balance Board for assessment of standing balance. Gait Posture, 31: 307-310

8. Elinda Ai-Lim Lee, Kok Wai Wong, Chun Che Fung (2010): " How does desktop Virtual Reality enhance learning outcomes ? A structural equation modeling approach " Computers \& Education, Vol (55), No (4)

9. Elirda, Kokwri, Chunche (2009): Learning Effectiveness in a Desktop Virtual RealityBased Learning Environment, $17^{\text {th }}$ International Conference on Computers in Education, Hong Kong.

10. Epstein, zach (2013): microsoft says xbox 360 sales have surpassed 76 million units, kinect sales.

11. Gama MC, Sousa F, Dos Reis I, Gobatto (2016); Reliability of the Three-minute All-out Test for Nonmotorized Treadmill Tethered Running.Int J Sports Med. 12. Gerd Hokhmut (1978): biomechanics and methods of scientific research and sports movements, translation Kamal A Hamid, Suleiman Hassan, Dar almaaref, Cairo,pp17.

13. Hanley, B., \& Mohan, A. (2014); Changes in gait during constant pace treadmill running. Journal of Strength and Conditioning Research, 28, 1219-1225.

14. Hsiu, Ulrich, Shu-Sheng (2010): Investigating Learners Attitudes Toward Virtual Reality Learning Environments: Based on a Constructivist Approach, Computers \& Education, Vol (55), No (2) .

15. IruthayarajahJ, McIntyr e A, Cotoi A, Macaluso S,2,3, Teasell $R(2016):$ The use of virtual reality for balance among individuals with chronic stroke: a systematic review and metaanalysis. International Journal of Sports Medicine

16. Jeong HW(2008): The Effects of Visual Perception Training Program on the Visual Perception and Eyehand Coordination Skills of Children with Spastic Cerebral Palsy, Dankook university Graduate school of special education..

17. Joan Mccomas et al (2006) : " Effectiveness of Virtual Reality for Teaching Pedestrian Safety ", 
Cyberpsychology\& Behavior, Vol (5), No (3) .

18. Lee IW, Kim YN, Lee DK.(2015): Effect of a virtual reality exercise program accompanied by cognitive tasks on the balance and gait of strokepatients.

19. Meheryar Nooriafshar (2005): The Use of Virtual Reality in Education, Journal of Interactive Learning Research , Vol (15), No (1) 20. Mufti Ibrahim Hammad (2010); sports training for juniors and successful coach Dar al-Hadith book - Cairo 21. Mulroy S, Klassen, Gronley J, Eberly, Brown D, Sullivan (2010): Gait parameters associated with responsiveness to treadmill training with body-weight support after stroke: an exploratory study. ncbi.nlm.nih.gov/pubmed/2002 2996

22. Talha Hussain Hossam El-Din and others (2014): The ABCs of Movement Science, the first edition, the modern printing center.pp177

\section{Zainab}

Mohamed

Lemine (2008): Problems on Education Technology, Dar AlHuda for publication and distribution, Minya.

24. www.who.int/mediacentre/ factsheets/fs344/en/ World Health Organization 2012.
25. www.:en.wikipedia.org/wi ki/Pulse-width_modulation. 26. https://en.wikipedia.org/wi ki/Arduino.

27. https://en.wikipedia.org/wi ki/PID_controller. 